RAD Conference Proceedings, vol. 4, pp. 149-154, 2020

ISSN 2466-4626 (online) | DOI: 10.21175/RadProc.2020.31

www.rad-proceedings.org

\title{
ESTIMATION OF RADIATION DOSAGE FOR TRAUMATIC PATIENTS IN MAJMAAH AREA, SAUDI ARABIA
}

\author{
Yousif Abdallah* \\ Radiological Science and Medical Imaging Department, \\ College of Applied Medical Science, Majmaah University, Majmaah, Saudi Arabia
}

\begin{abstract}
Radiation Exposure is the main hazard in medical $x$-rays investigations. The objective of this work was to study the attended radiation dose measured in the Majmaah area. Furthermore, to measure the radiation dose level for different examinations in conventional $x$-rays. Thus, conventional $x$-rays examination of traumatic patients. A sample of 700 patients was evaluated using at King Khaled Hospital-Majmaah. The average and range of exposure parameters were $73.5 \pm 9.1(65.9-124.9) \mathrm{KVp}$ and $2.7 \pm 0.71$ (o.2 - 9.6) $\mathrm{mAs}$ for $X$-ray exposure factors, respectively . The measured Entrance Surface Air Kerma (ESAK) dose for chest (PA), skull ((AP) and (LAT.)), Lumbosacral ((AP) and (LAT.)) In addition, knee joints ((AP) and (LAT.)) were $0.20+0.07$ with range of (o.13-0.37) $\mathrm{mGy},(0.86 \pm 0.01)$ with range of $(0.09-2.92) \mathrm{mGy}$ and $0.09+0.02$ with range of $(0.04-0.17) \mathrm{mGy},(0.10 \pm 0.02$ with range of $(0.04-0.17) \mathrm{mGy}$ and $0.1+0.02$ with range of $(0.03-0.16) \mathrm{mGy}$ and $0.86 \pm 0.01$ with range of $(0.09-2.92) \mathrm{mGy}$ respectively. The study was concluded that most of the procedures were done in King Khalid Hospital-Majmaah were in the permissible limits. In dose measurement techniques, the machine and patient-related factors must be fixed for accurate results.
\end{abstract}

Keywords: Traumatic patients, Radiology, radiation, protection, Saudi Arabia

\section{INTRODUCTION}

Trauma is an injury affects and leads to life threaten and psychological and physical impact. Recently, in Saudi Arabia, the number of traffic accidents and their effects has increased significantly [1-3]. There is no clear protocol to describe radiation exposure of patients during radiation investigations. The usual radiation exposure varies between 10-100 mGy, which may increase the possibility of cancer incidence especial among population who high exposed [4-5]. The traumatic x-rays imaging considers one of the commonest diagnostic tools used to analyze and identify the pathological conditions [6-8]. It contributes by significant radiation dose amount to patients. Since the applications of traumatic radiology are growing quickly, it is crucial issue to appraise the radiation dosages during the examination and try to reduce them as much as possible [9-10]. The demographic data and exposure measurements for all patients who admitted for radiology department should be collected. Radiation Exposure is main hazard in medical x-rays investigations [11]. Those exposures are results from improper use of equipment and high exposure factors. The exposure of diverse dose standards for the same medical investigation is a sufficient purpose to draw attenuation to this matter. Radiation exposure can reason severe injuries and possible cancerous attending. Radiation Medical
Imaging is used commonly for trauma assessment [1214]. Those imaging examinations are helped in the appropriate analysis of numerous disorders. They provide quick and precise analysis for the emergency GPs for the judgment of the serious grievances in patients, particularly in some patients that their injuries are difficult to diagnose them [15-16]. There are many hazards associated with the radiation exposure which included the acute (radiation injury) and chronic exposure effects (cancer). The acute effects include organs injuries, which can possibly lead to decease at high dosage [17-18]. Most of the radiographical investigations do not cause acute injuries to the patients due their low energy less than 10 mGy. The chronic effects of radiation are included the dangerous of cancer and genetic disorders [19-20]. The measurement of the radiation dose from traumatic radiological examinations was conducted globally [2124].

\section{MATERIALS AND METHODS}

The sample of this work comprised of 700 patients from radiology department of King Khaled Hospital, Majmaah, Saudi Arabia. IRB of King Abdelaziz City of Science and Technology (KACST) and Ministry of Health, Saudi Arabia approved all the methods of data collection that were performed in this study. Patients' data included in this study were patient demographic information and imaging protocols were documented.

\footnotetext{
"y.yousif@mu.edu.sa
} 
Y. Abdallah, Radiation dosage for patients in Majmaah, RAD Conf. Proc., vol. 4, 2020, 149-154

Entrance Surface Air Kerma (ESAK) (mGy) was measured for chest, Skull, lumbosacral joint and knee joint $\mathrm{x}$-rays examination. This dose was used to quantify the ionizing radiation for the traumatic patients in radiology department. The measured dose was compared with different previous studies nationally and internationally. Data analyzed by using SPSS program software version (22; SPSS Inc., Chicago, IL) and the results presented in form of graphs and tables. TLDS devices were used in this study for dose measurement. Those devices were made of different electrodes (LIF: MG and $\mathrm{Cu}$ ). Those devices have measurement range of .oo1 rad to $100 \mathrm{~Gy}$. The reading of the devices was made directly after the irradiation. The radiographic equipment used Siemens imaging system.

\section{RESUlTS}

Table 1 shows mean age of the patients for both genders in this study and the exposure factors logged for each patient during the examination of each projection. The exposure factors logged were projection, $\mathrm{KVp}, \mathrm{mA}$, time, field size, part under examination and tube to film distance. This study involved 700 patients undergoing chest, skull, lumbosacral and knee joints x-ray examinations in radiology departments at King Khalid Hospital in Majmaah. For the patients in this study, $80 \%$ of the patients were males and $30 \%$ were females.

Table 2 shows the measured dose in king Khalid Hospital-Majmaah, national and international hospitals. Those doses likened with national and worldwide radiation dose limits. The measured ESAK for chest (PA), Skull (Anteroposterior and lateral), Lumbosacral joint (Anteroposterior and lateral) and knee joint (Anteroposterior and lateral) were recoded (Table 3). Those amounts were dissimilar in king
Khalid-Majmaah and other Saudi hospitals (KKUH, KACST and SFH) and international places (UK, IAEA, UK, China, Greece, HPS, Canada and Italy. The measured dose for chest x-rays in this study was $0.20+$ $0.07 \mathrm{mGy}$ with range of (0.13-0.37 mGy), while the lowermost amount level was $0.02 \mathrm{mGy}$ in Health Physics Society (HPS) while the highest level was 0.69 $\mathrm{mGy}$ in Greece. The measured dose for PA projection of skull $\mathrm{x}$-rays in this study was $0.86+0.01 \mathrm{mGy}$ with range of (0.09-2.92 $\mathrm{mGy}$ ), while the lowest dose level was $0.86 \mathrm{mGy}$ in in king Khalid-Majmaah while the uppermost level was 5.0 mGy in IAEA. Nevertheless, the measured dose for lateral projection of skull $\mathrm{x}$-rays in this study was $0.09+0.02 \mathrm{mGy}$ with range of (0.04$0.17 \mathrm{mGy}$ ), while the lowest dose level was $0.69 \mathrm{mGy}$ in Nigeria while the uppermost level was $3.00 \mathrm{mGy}$ in IAEA.

The measured dosage for AP projection of Lumbosacral joint $x$-rays in this study was $8.27+3.01$ mGy with range of (o.20 -22.3 mGy), the lowermost dose level was $0.20 \mathrm{mGy}$ in King Khalid- Majmaah, while the highest level was $40 \mathrm{mGy}$ in KACST. Nevertheless, the measured dosage for lateral projection of Lumbosacral joint $x$-rays in this study was $10.04+3.43 \mathrm{mGy}$ with range of (2.05-29.21 mGy), which was the lowest dose level was 1.17 in King Khalid University Hospital (KKUH), while the highest level was $44 \mathrm{mGy}$ in Greece (Table 3).

The measured dose for AP projection of knee joint $\mathrm{x}$-rays in this study was $0.10+0.02 \mathrm{mGy}$ with range of (0.02-0.17 mGy), which was the lowest dose level while the highest level was $0.30 \mathrm{mGy}$ in King Khalid University Hospital (KKUH). Nevertheless, the measured dose for lateral projection of knee joint $\mathrm{x}$ rays in this study was $0.1+0.02 \mathrm{mGy}$ with range of (0.03-0.18 mGy), which was the lowest dose level while the highest level was $0.33 \mathrm{mGy}$ in King Khalid University Hospital (KKUH) (Table 3).

Table 1. Patient x-rays image acquisition features

\begin{tabular}{|l|c|c|c|c|c|c|c|}
\hline \multicolumn{7}{|c|}{ Male patients (male: $\mathrm{n}=560,80 \%$, Female: $\mathrm{n}=140,20 \%$ ), Age : 37.1 + 13.3 years with range of (18-63) years } \\
\hline \multirow{2}{*}{ Parameters } & Chest & \multicolumn{2}{|c|}{ Skull } & \multicolumn{3}{|c|}{ L/S } & \multicolumn{2}{|c|}{ Knee joint } \\
\cline { 2 - 8 } & PA & AP & LAT & AP & LAT & AP & LAT \\
\hline Tube voltage (kVp) & $124.8+0.14$ & 124.5 & 124.9 & $75.8+7.8$ & $83.8+7.2$ & $56.9+5.1$ & $55.7+3.2$ \\
\hline Tube current (mAs) & $1.6+0.79$ & 1 & 2.2 & $22.5+3.9$ & $22.4+4.1$ & $4.9+1.1$ & $4.9+1.06$ \\
\hline $\begin{array}{l}\text { Tube to patient distance } \\
\text { (cm) }\end{array}$ & $178.7+11.6$ & & & $113+4.14$ & $114.2+5.2$ & $106.2+9.9$ & $115+11.5$ \\
\hline Dose (mGy) & $0.20+0.07$ & $0.86+0.01$ & $0.9+0.02$ & $8.27+3.01$ & $10.04+3.43$ & $0.10+0.02$ & $0.1+0.02$ \\
\hline
\end{tabular}

*AP: anteroposerior, LAT: lateral

Table 2. Shows the mean and standard deviation of radiation dose (ESAK) measured in King Khalid Hospital-Majmaah, national and International hospitals for chest, Skull, lumbosacral joint and knee joint

\begin{tabular}{|l|c|c|c|}
\hline \multicolumn{1}{|c|}{ Projection } & Mean + STdev. & Minimum value (mGy) & Maximum value (mGy) \\
\hline PA Chest & $0.20+0.07$ & 0.13 & 0.37 \\
\hline AP Skull & $0.86+0.01$ & 0.09 & 0.92 \\
\hline Lateral skull & $0.9+0.02$ & 0.04 & 22.3 \\
\hline AP Lumbosacral & $8.27+3.01$ & 0.20 & 29.21 \\
\hline Lateral Lumbosacral & $10.04+3.43$ & 2.05 & 0.17 \\
\hline AP knee & $0.10+0.02$ & 0.02 & 0.18 \\
\hline Lateral knee & $0.1+0.02$ & 0.03 & \\
\hline
\end{tabular}


Y. Abdallah, Radiation dosage for patients in Majmaah, RAD Conf. Proc., vol. 4, 2020, 149-154

Table 3. The mean values of ESAK (mGy) of chest examination for all age groups of the study sample

\begin{tabular}{|c|c|c|c|c|c|c|c|c|c|}
\hline Exam & $\begin{array}{c}\text { Present } \\
\text { Study }\end{array}$ & KKUH & SFH & KACST & IAEA & USA & UK & MAY.* & Nig. \\
\hline Chest (PA) & 0.20 & 0.135 & 0.220 & 0.4 & 0.4 & 0.25 & 0.15 & 0.9 & 0.45 \\
\hline Skull (AP) & 0.86 & 0.119 & - & 5.0 & 5.0 & 2.25 & 1.8 & 4.8 & 0.77 \\
\hline Skull (LAT) & 0.9 & - & - & - & 3.0 & - & 1.1 & 2.4 & 0.69 \\
\hline L/S (AP) & 8.27 & 0.655 & 5.23 & 40 & 10.0 & 6.54 & $5 \cdot 7$ & $7 \cdot 5$ & 0.99 \\
\hline L/S (LAT) & 10.04 & 1.173 & 8.99 & 40 & 30 & - & 10.0 & 13.4 & 1.43 \\
\hline Knee (AP) & 0.1 & 0.305 & 0.260 & - & - & - & 0.3 & - & 0.38 \\
\hline Knee (LAT) & 0.1 & 0.334 & 0.240 & - & - & - & 0.3 & - & 0.69 \\
\hline
\end{tabular}

*MAY.: Malaysia, Nig.: Nigeria, KKUH: King Khalid University Hospital-Riyadh, SFH: Security Force Hospital, IAEA: International Atomic Energy Agency

\section{Discussion}

This experimental study performed to measure of dose received by organs in chest (PA), skull (AP and LAT), lumbosacral joint (AP, LAT), cervical (AP, LAT) and knee joint (AP, LAT) x-ray examination. A total of 700 patients were examined in two radiology departments in King Khalid-Majmaah hospital. The results of this study was compared with other scientist studies nationally (Saudi Arabia) and internationally. The former studies showed different results in dose of patients such as Abdelhalim, M. (2010). There were many factors that might affect the results of the dose measurement such as patent related factors (BMI), technical factors (projection, techniques and exposure factors selection) and machine factors (machine and TLDs calibration and service). The dose increased with BMI, which was agreed with Inkoom et al (2014) and Freitas et al (2009). This study highlights the importance of the quality control program in check the machine performance and reduction of radiation dosage to both patients and healthcare staff. Recent studies showed that there were large amounts of radiation exposure in diagnostic radiology due to its widely utilization especially in emergency department Pauwels et al, (2015), Al-Abdulsalam and Brindhaban (2014), Tian et al, (2015), Parakh et al (2015) and Lukasiewicz et al (2014). This study recommends selecting the mean radiation dose of chest, skull, cervical spine and knee joints as guidelines for radiation examination in Majmaah area, hospitals, because they were least compared with other studies. Therefore, the calculated dose of the chest x-rays was $0.20+0.07 \mathrm{mGy}$ with range of $0.13-0.37 \mathrm{mGy}$. The calculated radiation dose for skull was $0.86+0.01$ and $0.09+0.02 \mathrm{mGy}$ for $\mathrm{AP}$ and lateral projections, respectively. The calculated radiation dose for lumbosacral joint was $8.27+3.01$ and $10.04+3.43$ $\mathrm{mGy}$ with range of $0.20-29.21 \mathrm{mGy}$ for AP and lateral projections, respectively. The calculated radiation dose for knee joint was $0.10+0.02$ and $0.1+0.02 \mathrm{mGy}$ with range of $0.02-0.18 \mathrm{mGy}$ for $\mathrm{AP}$ and lateral projections, respectively.

The lowest dose for chest x-rays level was $0.02 \mathrm{mGy}$ in Health Physics Society while the uppermost level was $0.69 \mathrm{mGy}$ in Greece. While the lowest dose of AP skull x-rays level was in Health Physics Society (HPS) while the highest level was in Greece. Nevertheless, the measured dose for lateral projection of lateral skull $\mathrm{x}-$ rays in this study was the lowest dose level, while the highest level was in Greece. The lowest dose level for AP projection of Lumbosacral joint x-rays in King Khalid- Majmaah, while the highest level was $40 \mathrm{mGy}$ in KACST. Nevertheless, the measured dose for lateral projection of lateral projection Lumbosacral joint $\mathrm{x}^{-}$ rays in this study was the lowest dose level was in King Khalid University Hospital (KKUH), while the highest level was 44 mGy in Greece.

\section{CONCLUSION}

Finally, in this study, it was found that radiation amounts for chest (PA), skull (AP and LAT), lumbosacral joint (AP, LAT), cervical (AP, LAT) and knee joint (AP, LAT) for the entire examination were higher. The ESAKs for conventional radiology were lower in AP than those for lateral projection and LA/LS respectively. Unlike the previous studies, the dose in $\mathrm{L} / \mathrm{S}$ radiography was higher in conventional radiography compared to other techniques. Recently digital and computed radiography are becoming more popular due to the important advantage of digital imaging is cost and access. Therefore, the importance of dose optimization during conventional radiology imaging must be considered. This study concluded that the doses for chest, skull, cervical and knee joints were lower than the other alike studies nationwide and globally. The dose in L/S radiography was higher in conventional radiography compared to other techniques. Recently utilization of automatic exposure calculator was more useful and reduces the dose to the patients. Computer radiography is gratifying, more popular due to its value, access and good dose changes. This study will assist the investigators to discover the critical parts of radiation protection in traumatic radiology department that many investigators were not able to explore.

Conflict of Interest: No potential conflict of interest relevant to this article was reported.

Ethical approval: The Institutional Ethics Committees of KACST, KSA with registration number of $H-O 1-R-O 12, O H R P / N I H$, USA with registration number IRBoOO10471 and Federal Wide Assurance 
Y. Abdallah, Radiation dosage for patients in Majmaah, RAD Conf. Proc., vol. 4, 2020, 149-154

NIH, USA with registration number FWAooo18774 were approved the study. The ethical committee of the Deanship of Scientific Research, at Majmaah University also approved this research with registration number MUREC- Nov.2l/COM-201 8/9.

Acknowledgements: The author is thankful to the Deanship of Scientific Research, at Majmaah University for funding this research. The paper is a part of the research done within the project 38/147.

\section{REFERENCES}

1. M. Mahesh, The Essential Physics of Medical Imaging, $3^{\text {rd }}$ ed., Medical Physics, 2013, pp. 100-120. PMid: 28524933 https://doi.org/10.1118/1.4811156

2. C.J. Martin, D.G. Sutton, C.M. West, E.G. Wright, "The radiobiology/radiation protection interface in healthcare," J. Radiol. Prot., vol. 29, no. 2A, pp. A1-A20, Jun. 2009.

PMid: 19454808

https://doi.org/10.1088/0952-4746/29/2A/So1

3. E.J. Dawe, E. Fawzy, J. Kaczynski, P. Hassman, S.H. Palmer, "A comparative study of radiation dose and screening time between mini $\mathrm{C}$-arm and standard fluoroscopy in elective foot and ankle surgery," Foot and Ankle Surgery, vol. 17, no. 1, pp. 33-36, Mar. 2011.

PMid: 21276563

https://doi.org/10.1016/j.fas.2010.01.001

4. G. Compagnone, M.C. Baleni, L. Pagan, F.L. Calzolaio, L. Barozzi, C. Bergamini, "Comparison of radiation doses to patients undergoing standard radiographic examinations with conventional screen-film radiography, computed radiography and direct digital radiography," Br. J. Radiol., vol. 79, pp. 899-904, Nov. 2006

PMid: 17065288

https://doi.org/10.1259/bjr/57138583

5. D. Hart, B.F. Wall, "UK population dose from medical X-ray examinations," Eur. J. Radiol., vol. 50, no. 3, pp. 285-291, Jun. 2004.

PMid: 15145489.

https://doi.org/10.1016/So720-048X(03)00178-5

6. A. Herrmann et al., "Chest imaging with flat-panel detector at low and standard doses: comparison with storage phosphor technology in normal patients," Eur. Radiol., vol. 12, pp. 385-390, 2002.

PMid: 11870439 https://doi.org/10.1007/s00330-001-1166-4

7. D.F. Walsh, A.P. Thome, K.S. Mody, A. Eltorai, A.H. Daniels, M.K. Mulcahey, "Radiation safety education as a component of orthopedic training," Orthopedic Reviews, vol. 11, no. 1, article no. 7883, pp. 20-23, Mar. 2019.

PMid: 30996841

https://doi.org/10.4081/or.2019.7883

8. S. Bahari, S. Morris, D. Broe, C. Taylor, B. Lenehan, J. McElwain, "Radiation exposure of the hands and thyroid gland during percutaneous wiring of wrist and hand procedures," Acta Orthop. Belg., vol. 72, no. 2, pp. 194-198, Apr. 2006.

PMid: 16768265 .

9. K. Mohamad, A Abdelhalim, O. Reuqaya, A. Mohammad, "Assessment of Patient Doses Levels During X-Ray Diagnostic Imaging Using TL Dosimeters and Comparison with Local and International Levels," Trends in Medical Research, vol. 3, no. 2, pp. 72-81, 2008. https://doi.org/10.3923/tmr.2008.72.81

10. E. Vañó et al., "ICRP Publication 135: Diagnostic Reference Levels in Medical Imaging," Ann. ICRP, vol. 46, no. 1, pp. 1-144, Oct. 2017.

PMid: 29065694

https://doi.org/10.1177/0146645317717209

11. E. Vañó, M. Rosenstein, J. Liniecki, M.M. Rehani, C.J. Martin, R.J. Vetter, "ICRP Publication 113. Education and training in radiological protection for diagnostic and interventional procedures," Ann. ICRP, vol. 39, no. 5, pp. 7-68, Oct. 2009.

PMid: 21788173

https://doi.org/10.1016/i.icrp.2011.01.002

12. J. Valentin, "Avoidance of radiation injuries from medical interventional procedures," Ann. ICRP vol. 30, no. 2, pp. 7-67, Jun. 2000.

PMid: 11459599

https://doi.org/10.1016/So146-6453(01)00004-5

13. D. Papadimitriou et al., "Patient Dose, Image Quality and Radiographic Techniques for Common X-ray Examinations in Two Greek Hospitals and Comparison with European Guidelines," Radiat. Prot. Dosimetry, vol. 95, no. 1, pp. 43-48, May 2001. https://doi.org/10.1093/oxfordjournals.rpd.a006521

14. C.L. Li, Y. Thakur, N.L. Ford, "Comparison of the CTDI and AAPM report No. 111 methodology in adult, adolescent, and child head phantoms for MSCT and dental CBCT scanners," J. Med. Imaging, vol. 4, no. 3, article no. 031212, Jul. 2017.

PMid: 28983492

PMCid: PMC5621782

https://doi.org/10.1117/1.JMI.4.3.031212

15. B.M. Moore, S.L. Brady, A.E. Mirro, R.A. Kaufman, "Size-specific dose estimate (SSDE) provides a simple method to calculate organ dose for pediatric CT examinations," Med. Phys., vol. 41, no. 7, article no. 071917, Jul. 2014

PMid: 24989395

PMCid: PMC5148074

https://doi.org/10.1118/1.4884227

16. C. Descamps, M. Gonzalez, E. Garrigo, A. Germanier, D. Venencia, "Measurements of the dose delivered during CT exams using AAPM Task Group Report No. 111," J. Appl. Clin. Med. Phys., vol. 13, no. 6, pp. 293-302, Nov. 2012.

PMid: 23149785

PMCid: PMC5718533

https://doi.org/10.1120/jacmp.v13i6.3934

17. S. Inkoom, C. Schandorf, M. Boadu, G. Emi-Reynolds, A. Nkansah, "Adult medical X-ray dose assessments for computed tomography procedures in Ghana - A review," Journal of Agricultural Science and Technology, vol. 19, no. 1-2, pp 1-9, 2014.

18. W. Muhogora, M.M. Rehani, "Review of the status of radiation protection in diagnostic radiology in Africa," J. Med. Imaging, vol. 4, no. 3, article no. 031202, Jul. 2017.

PMid: 28630886

PMCid: PMC5468545

https://doi.org/10.1117/1.JMI.4.3.031202

19. L.T. Dauer et al., "Status of NCRP Scientific Committee 1-23 Commentary on Guidance on Radiation Dose Limits for the Lens of the Eye," Health Phys., vol. 110, no. 2, pp. 182-184, Feb. 2016. PMid: 26717175 PMCid: PMC4697269 https://doi.org/10.1097/HP.0000000000000412

20. A. Nemto, C. Czink, D. Haba, A. Gahleitner, "Cone beam CT: A current overview of devices," Dentomaxillofacial Radiology, vol. 42, no. 8, article no. 20120443, Jun. 2013.

PMid: 23818529 
PMCid: PMC 3922261

https://doi.org/10.1259/dmfr.20120443

21. R. Pauwels, K. Araki, J.H. Siewerdsen, S.S. Thongvigitmanee, "Technical aspects of dental CBCT: state of the art," Dentomaxillofacial Radiology, vol. 44, no. 1, article no. 20140224, Oct. 2015.

PMid: 25263643

PMCid: PMC4277439

https://doi.org/10.1259/dmfr.20140224

22. W.A. Kalender, "Dose in x-ray computed tomography," Phys. Med. Biol., vol. 59, no. 3, pp. 129-150, Jan. 2014.

PMid: 24434792

https://doi.org/10.1088/0031-9155/59/3/R129

23. X. Tian, X. Li, W.P. Segars, E.K. Paulson, D.P. Frush, E. Samei, "Pediatric chest and abdominopelvic CT: Organ dose estimation based on 42 patient models," Radiology, vol. 270, no. 2, pp. 535-547, Feb. 2014.

PMid: 24126364

PMCid: PMC4228746

https://doi.org/10.1148/radiol.13122617

24. A. Al-Abdulsalam, A. Brindhaban, "Occupational radiation exposure among the staff of departments of nuclear medicine and diagnostic radiology in Kuwait," Med. Princ. Pract., vol. 23, no. 2, pp. 129-133, 2014

PMid: 24356092

PMCid: PMC5586859

https://doi.org/10.1159/000357123

25. A. Lukasiewicz et al., "Radiation dose index of renal colic protocol CT studies in the United States: A report from the American College of Radiology National Radiology Data Registry," Radiology, vol. 271, no. 2, pp. 445-451, May 2014.

PMid: 24484064

PMCid: PMC5341688

https://doi.org/10.1148/radiol.14131601

26. A. Parakh, A. Euler, Z. Szucs-Farkas, S.T. Schindera, "Transatlantic Comparison of CT Radiation Doses in the Era of Radiation Dose-Tracking Software," Am. J. Roentgenol., vol. 209, no. 6, pp. 1302-1307, Dec. 2017.

PMid: 28898129

https://doi.org/10.2214/AJR.17.18087

27. D. Hart, M.C. Hillier, B.F. Wall, "National reference doses for common radiographic, fluoroscopic and dental X-ray examinations in the UK," Br. J. Radiol., vol. 82, no. 973, pp. 1-12, 2009.

PMid: 18852213 https://doi.org/10.1259/bjr/12568539

28. N. Muhammad, M. Abdul Karim, H. Hassan, K. Kamarudin, J. Wong, K. Hoong, "Diagnostic Reference Level of Radiation Dose and Image Quality among Paediatric CT Examinations in A Tertiary Hospital in Malaysia," Diagnostics, vol. 10, no. 8, article no. 591, Aug. 2020.

https://doi.org/10.3390/diagnostics10080591

29. M.B. Freitas, E.M. Yoshimura, "Diagnostic reference levels for the most frequent radiological examinations carried out in Brazil," Rev. Panam. Salud. Publica, vol. 25, no. 2, pp. 95-104, Feb. 2009. PMid: 19531303

https://doi.org/10.1590/s102049892009000200001

30. R.A. Hayda, R.Y. Hsu, J.M. DePasse, J.A. Gil, Radiation Exposure and Health Risks for Orthopaedic Surgeons," J. Am. Acad. Orthop. Surg., vol. 26, no. 8, pp. 268-277, Apr. 2018.

PMid: 29570497

https://doi.org/10.5435/JAAOS-D-16-00342

31. C.M. Stahl, Q.C. Meisinger, M.P. Andre, T.B. Kinney,

I.G. Newton, "Radiation Risk to the Fluoroscopy
Operator and Staff,” Am. J. Roentgenol., vol. 207, no. 4, pp. 737-744, Oct. 2016.

PMid: 28829623 https://doi.org/10.2214/AJR.16.16555

32. M.L. Wang, C.E. Hoffler, A.M. Ilyas, P.K. Beredjiklian, C.F. Leinberry, "Fluoroscopic Exposure with Use of Mini-C-Arm During Routine Hand Surgery: A Prospective Comparison of Hand Versus Eye Radiation Dosage," J. Surg. Orthop. Adv., vol. 26, no. 2, pp. 102-105, 2017.

PMid: 28644122

33. M.M. Vosbikian, A.M. Ilyas, D.D. Watson, C.F. Leinberry, "Radiation exposure to hand surgeons' hands: A practical comparison of large and mini C-arm fluoroscopy," J. Hand Surg., vol. 39, no. 9, pp. 1805-1809, Jul. 2014

PMid: 25086796

https://doi.org/10.1016/j.jhsa.2014.06.133

34. C.B. Fuller, M.D. Wongworawat, B.B. Riedel, "Radiation Exposure and Hand Dominance Using Mini C-Arm Fluoroscopy in Hand Surgery," Hand, vol. 11, no. 2, pp. 188-191, 2016.

PMid: 27390561

PMCid: PMC4920527

https://doi.org/10.1177/1558944715627224

35. J.R.M. van Rappard, T. de Jong, W.A. Hummel, M.J. Ritt, C.M. Mouës, "Radiation Exposure to Surgeon and Assistant During Flat Panel Mini C-Arm Fluoroscopy in Hand and Wrist Surgical Procedures," J. Hand. Surg., vol. 44, no. 1, pp. 68.e1-68.e5, 2018.

PMid: 29934087

https://doi.org/10.1016/j.jhsa.2018.05.010

36. C.N. Kesavachandran, F. Haamann, A. Nienhaus, "Radiation exposure of eyes, thyroid gland and hands in orthopaedic staff: A systematic review," Eur. J. Med. Res., vol. 17, article no. 28, Oct. 2012.

PMid: 23111028

PMCid: PMC 3554445 https://doi.org/10.1186/2047-783X-17-28

37. M.A. Abdelhalim, "Patient dose levels for seven different radiographic examination types," Saudi $J$. Biol. Sci., vol. 17, no. 2, pp. 115-118, Apr. 2010.

PMid: 23961066

PMCid: PMC3730880

https://doi.org/10.1016/i.sjbs.2009.12.013

38. A. Meghzifene, D.R. Dance, D. McLean H.M. Kramer, "Dosimetry in diagnostic radiology," Eur. J. Radiol., vol. 76, no. 1, pp. 11-14, Oct. 2010. PMid: 20655679

https://doi.org/10.1016/j.ejrad.2010.06.032

39. Y. Asada, T. Ichikawa, "Consideration of diagnostic reference levels for pediatric chest X-ray examinations," Radiol. Phys. Technol., vol. 12, no. 4, pp. 382-387, Dec. 2019.

PMid: 31473934

https://doi.org/10.1007/s12194-019-00533-7

40. A. Aroua, R. Bize, I. Buchillier-Decka, J.P. Vader, J.F. Valley, P. Schnyder, "X-ray imaging of the chest in Switzerland in 1998: A nationwide survey," Eur. Radiol., vol. 13, pp. 1250-1259, Jun. 2003. PMid: 12764639 https://doi.org/10.1007/s00330-002-1682-x

41. T. Lehnert et al., "Image-quality perception as a function of dose in digital radiography," Am. J. Roentgenol., vol. 197, no. 6, pp. 1399-1403, Dec. 2011.

PMid: 22109295

https://doi.org/10.2214/AJR.10.6269

42. M. Körner, C.H. Weber, S. Wirth, K.J. Pfeifer, M.F. Reiser, M. Treitl, "Advances in digital radiography: physical principles and system 
Y. Abdallah, Radiation dosage for patients in Majmaah, RAD Conf. Proc., vol. 4, 2020, 149-154

overview," Radiographics, vol. 27, no. 3, pp. 675-686, 2007.

PMid: 17495286

https://doi.org/10.1148/rg.273065075

43. C. Schaefer-Prokop, U. Neitzel, H.W. Venema, M. Uffmann, M. Prokop, "Digital chest radiography: An update on modern technology, dose containment and control of image quality," Eur. Radiol., vol. 18, no. 9, pp. 1818-1830, 2008.

PMid: 18431577

PMCid: PMC2516181

https://doi.org/10.1007/s00330-008-0948-3

44. A. Sulieman, M. Vlychou, I. Tsougos, K. Theodorou, "Radiation doses to paediatric patients and comforters undergoing chest X rays," Radiat. Prot. Dosimetry, vol. 147, no. 1-2, pp. 171-175, Sep. 2011. PMid: 21743069 https://doi.org/10.1093/rpd/ncr295

45. A. Suliman, E.H Elshiekh, "Radiation doses from some common paediatric X-ray examinations in Sudan," Radiat. Prot. Dosimetry, vol. 132, no. 1, pp. 64-72, 2008.

PMid: 18765402

https://doi.org/10.1093/rpd/ncn232 